\title{
Selective Estrogen Receptor Modulators and Phytoestrogens
}

Author

Affiliation
Tawakalitu Oseni, Roshani Patel, Jennifer Pyle, V. Craig Jordan

Fox Chase Cancer Center, Philadelphia, PA, USA

\author{
Key words \\ - tamoxifen \\ - raloxifene \\ phytoestrogens \\ - SERMs \\ selective estrogen receptor \\ modulators \\ - breast cancer \\ - chemoprevention
}

received May 5, 2008

revised August 19, 2008

accepted August 28, 2008

\section{Bibliography}

DOI 10.1055/s-0028-1088304

Planta Med 2008; 74: 1656-

1665

(c) Georg Thieme Verlag KG

Stuttgart · New York

Published online October 8 , 2008

ISSN 0032-0943

\section{Correspondence}

V. Craig Jordan, OBE, PhD. DSC

Alfred G. Knudson Chair of

Cancer Research

Fox Chase Cancer Center

333 Cottman Avenue

Philadelphia

PA 19111-2497

USA

Tel.: +1-215-728-7410

Fax: +1-215-728-7034

v.craig.jordan@fccc.edu

\section{Abstract \\ $\nabla$}

Scientific achievements in the last two decades have revolutionized the treatment and prevention of breast cancer. This is mainly because of targeted therapies and a better understanding of the relationship between estrogen, its receptor, and breast cancer. One of these discoveries is the use of synthetic selective estrogen modulators (SERMs) such as tamoxifen in the treatment strategy for estrogen receptor (ER)-positive breast cancer. Hundreds of thousands of lives have been saved because of this advance. Not only is tamoxifen used in the treatment strategy for patients who have breast cancer, but also for prevention in high-risk premenopausal women. Another synthetic SERM, raloxifene, which was initially used to prevent osteoporosis, is also as effective as tamoxifen for prevention in highrisk postmenopausal women. In certain regions of the world, particularly in Asia, a low incidence of breast cancer has been observed. These women have diets that are high in soy and low in fat, unlike the Western diet. Interest in the protective effects of soy derivatives has led to the research of phytoestrogens and metabolites of soy that are described by some as natural SERMs. As a result, many clinical questions have been raised as to whether phytoestrogens, which are also found in other natural foods, can protect against breast cancer. This article reviews the development and role of the more common SERMs, tamoxifen and raloxifene. In addition, this paper will also highlight the emerging studies on phytoestrogens and their similarity and dissimilarity to SERMs.

\section{Introduction \\ $\nabla$}

Great strides have been made in the last 25 years in the fight against breast cancer. One of the more notable developments has been the search for ways to prevent cancer. The development of selective estrogen receptor modulators (SERMs) has been a significant step towards achieving that goal. Tamoxifen, an antiestrogen in the breast and the pioneering SERM, has been the gold standard, and often the only choice in many countries for the treatment of breast cancer [1]. It also became the first drug ever to be approved by the United States (US) Food and Drug Administration (FDA) for the chemoprevention of breast cancer in high-risk women [1]. This chapter will review the development of tamoxifen the prototypical SERM and its use and development as a chemopreventive agent. In addition this article will also highlight the emerging information regarding phytoestrogens that are being regarded by some as natural SERMs.

\section{Background}

By the turn of the $20^{\text {th }}$ century it was known that oophorectomy in pre-menopausal women with metastatic breast cancer could cause regression of the disease [2], [3]. This showed a link between products produced by the ovaries and the growth of some breast cancers. The product was found to be estrogen [4]. In 1936, Professor Antoine Lascassagne hypothesized that breast cancer was caused by a special hereditary sensitivity to estrogen and suggested that the development of an estrogen antagonist could prevent disease [5]. Over twenty-five years later in 1962 Jensen and Jacobsen [6] described the estrogen receptor (ER) as the mediator of estrogen action, setting the stage for the manipulation of this receptor for multiple purposes [7].

Investigation of possible contraceptive agents led to the reinvention of ICI 46474 , a failed contraceptive agent, to become tamoxifen, the first targeted anti-cancer agent. The study of tamoxifen 
in the laboratory led to the finding that it inhibited the growth of ER-positive breast cancer cells in vitro [8]. In addition, animal studies showed that tamoxifen prevented rat mammary carcinogenesis [9], [10] but had a stimulatory effect on rat uterine weight [11]. The actions of non-steroidal antiestrogens were clearly not wholly explainable as estrogen agonists or antagonists and a model to describe their unique actions led to the development of the SERM concept [12], [13], [14].

\section{What are SERMs?}

$\nabla$

SERMs are synthetic non-steroidal agents that bind to the ER and produce a change in the biological activity of the receptor depending on the tissue type. The primary target site for SERMs, the ER, is a nuclear receptor. To fully understand the unique nature of SERMs the actions of estrogen on the body must be revisited. Estrogen in premenopausal women is primarily produced by the ovaries. There are multiple target sites for estrogen and it has various actions throughout the body. Estrogens decrease cholesterol levels by lowering the circulating low-density lipoproteins (LDL). Its actions also include maintenance of bone density in postmenopausal women, and hormonal regulation, and control of the menstrual cycle in premenopausal women. These actions are summarized in $\odot$ Fig. 1 . In contrast, the effect of SERMs depends on the target sites and is shown in $\odot$ Fig. $\mathbf{2}$.

A pure estrogen agonist would be one that stimulates the positive action of estrogen at all its targets. Conversely, a pure antagonist would inhibit all the actions of estrogen at all of its target sites. In contrast, SERMs have partial agonist and antagonist properties depending on the target site hence their uniqueness.

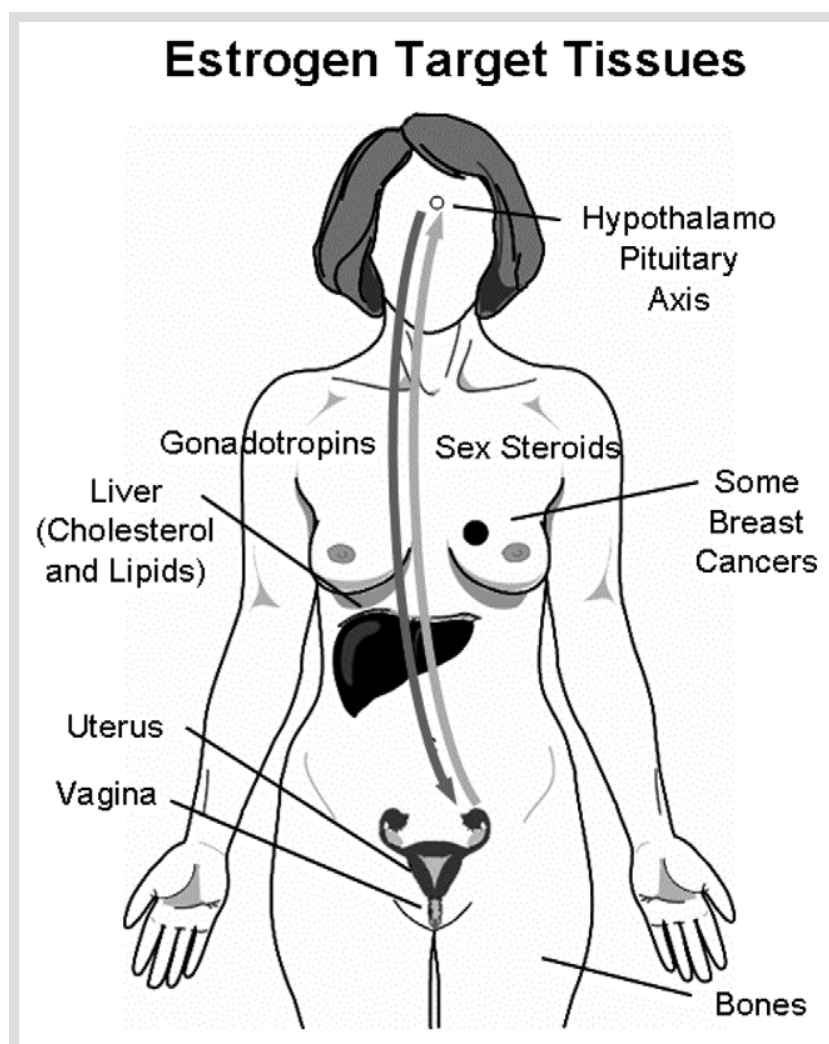

Fig. 1 The sites of action for estrogen.

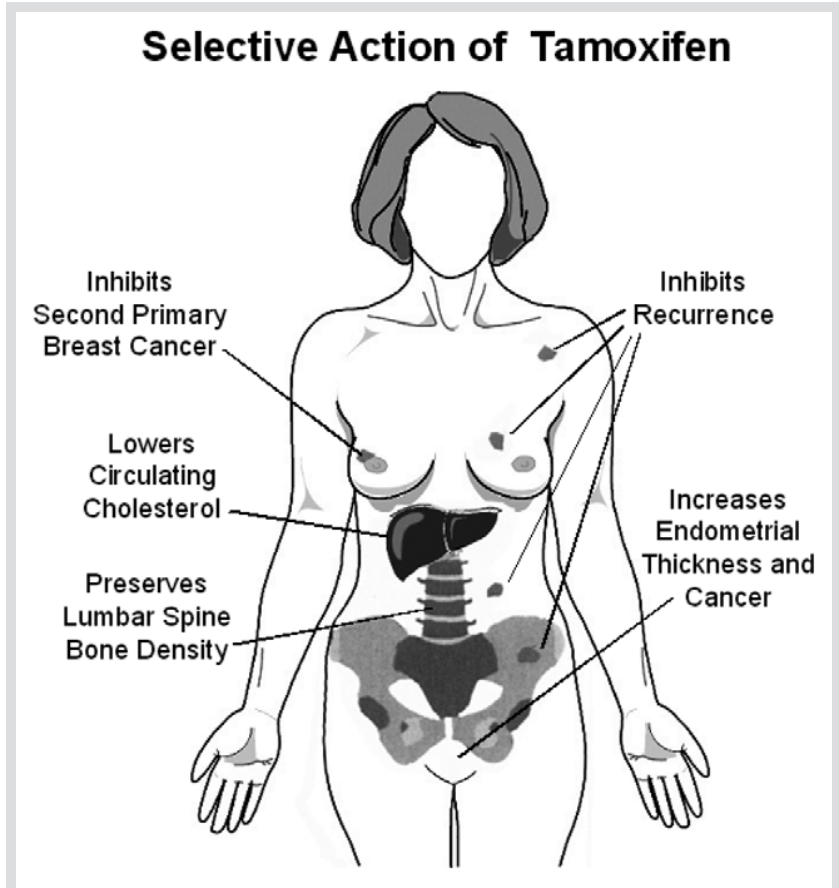

Fig. 2 The sites of action of tamoxifen.

Studies have shown that the partial agonist/antagonist properties depend on which associated coregulators are expressed when the receptor/ligand interaction occurs [15]. The details of the receptor/ligand interaction help us understand the mechanism of action of SERMs.

\section{Mechanism of action}

There are two aspects to the mechanism of action of SERMs: the pharmacokinetics or how the drug gets to the target site and the pharmacodynamics or what it does when it gets there. Tamoxifen ( $\bullet$ Fig. 3 ) is a lipophilic prodrug that is easily absorbed by the gut without modification and $98 \%$ is bound to albumin after entering the circulation. It undergoes extensive metabolism in the gastrointestinal (GI) tract and in the liver into its less active form $\mathrm{N}$-desmethyltamoxifen and two most active forms, 4-hydroxytamoxifen and endoxifen [16], [17], [18], [19]. Each of the hydroxylated metabolites results from first pass metabolism in the liver. These compounds enter the bloodstream via the enterohepatic circulation to reach their target sites [18], [20], [21]. The metabolites of tamoxifen are excreted via the fecal route as has been shown by animal studies using ${ }^{14} \mathrm{C}$ radiolabeled tamoxifen [22]. These studies demonstrate that $67 \%$ of these metabolites enter the enterohepatic circulation and undergo further metabolism several times until excretion by the GI tract [23], [24]. 4Hydroxytamoxifen, and endoxifen have the same affinity for the ER as estrogen. Other metabolites of tamoxifen do not have as much effect or affinity for the ER as they lack the 4-hydroxy group [18]. Recent studies demonstrate that the potent tamoxifen metabolite endoxifen is produced by the product of the CY2PD6 gene. In patients with mutations of the CYP2D6 gene or patients who take other medications that compete for the enzyme product, metabolism of tamoxifen to the potent metabolite endoxifen is affected and may therefore have less benefit [25], [26]. Raloxifene ( $\odot$ Fig. 3), another SERM, is a polyphenol, which undergoes rapid conjugation in the GI tract and in the liv- 


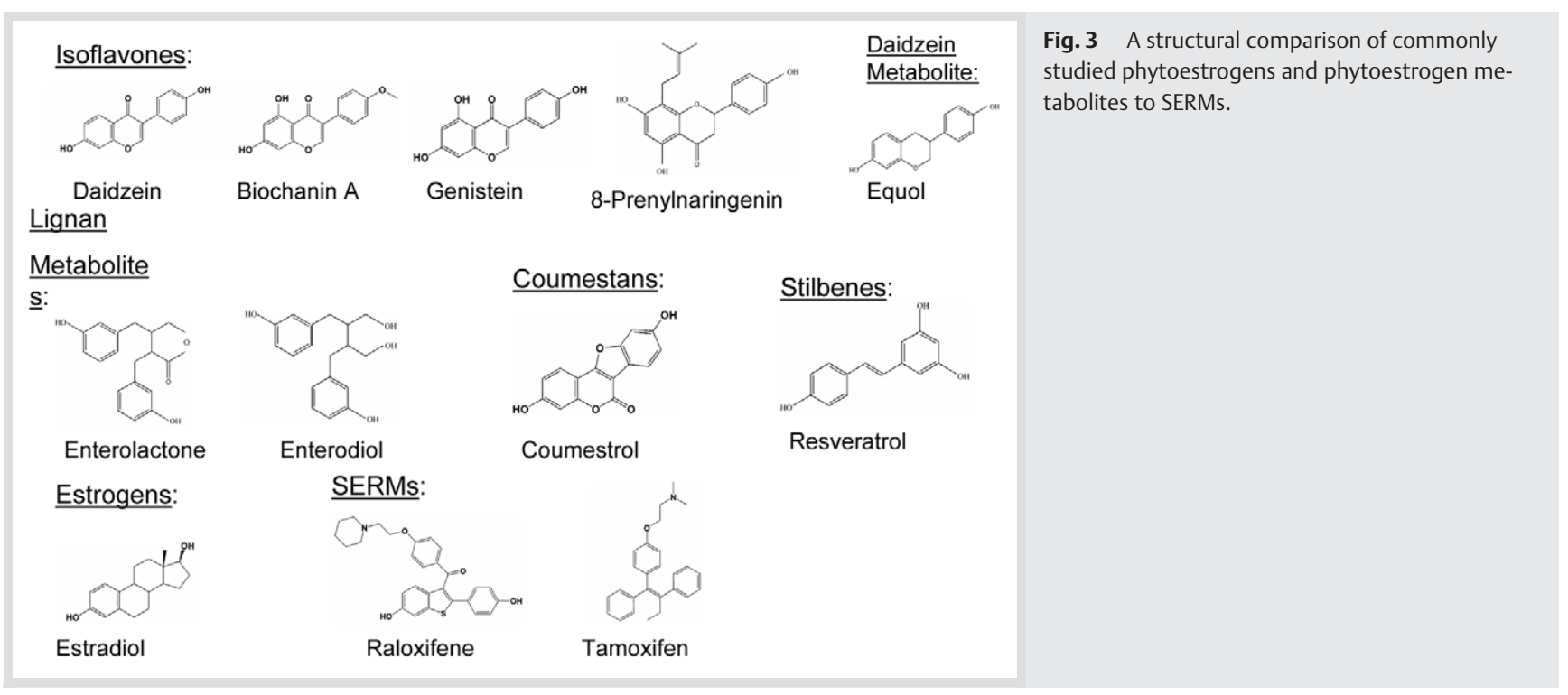

er. In addition it also undergoes phase 3 metabolism by gut flora. The bacteria directly glucuronidate and sulfate this compound so that it is excreted [26], [27]. Since the drug does not reenter the enterohepatic circulation, it does not reach its targets as efficiently as tamoxifen. Also, a smaller percent enters the circulation as only $2 \%$ is bound to albumin and the half-life of raloxifene is 27 hours [28]. As a result of differences in metabolism and bioavailability, raloxifene is not as useful an agent in patients who already have breast cancer [29].

There are two isoforms of the ER, ER $\alpha$ and $\operatorname{ER} \beta$ [6], [30] whose distribution and density varies depending on the target site. Both isoforms are found in the reproductive organs. Tamoxifen binds both receptors with equivalent affinity [31]. Endoxifen and 4-hydroxytamoxifen have similar affinities for both isoforms [32] and create similar gene expression profiles. Other ligands show preference for one isoform or the other, which may explain specific target tissue responses with various compounds. In many tissues, ER $\beta$ has anti-proliferative effects, whereas, ER $\alpha$ has proliferative effects [33]. Studies indicate that ER- $\beta$ has an inhibitory effect on ER- $\alpha$ [34], [36], [35]. However, the biology is more complex than a simple agonist/antagonist interaction between the two receptors. The ratio of $\operatorname{ER} \alpha$ to $\operatorname{ER} \beta$ at a target site may be important in determining the overall action of a SERM on that tissue. A high ratio may correlate with high levels of cellular proliferation while a low ratio implies the opposite [36].

In the past, the interaction between SERMs and the ER was thought to be a simple case of a ligand switching its target receptor on or off. Through further research it is now known that this interaction is a more complex and dynamic process. Studies using phage display created a fingerprint of exposed surfaces when tamoxifen or estrogen was bound to the ER. Different conformational changes occur in the ER depending on the ligand that binds to the ER. In addition, the fingerprint was different in ER$\alpha$ vs. ER- $\beta$ when they were bound to identical ligands [37]. The discovery of the steroid receptor co-activator protein (SRC1) helped further to elucidate this complex interaction [40]. The binding of an SERM to the ER results in a conformational change in the ER [41], which results in the exposure of different amino acids on the receptor and the binding of different coactivators. Since the discovery of SRC1, dozens of other co-activator and co-repressor molecules have been discovered; all of which play some role in receptor modulation [15].

Finally, another dimension of signaling pathways can modulate the ER. Activation of the ER by other growth factor pathways can result in resistance to SERMs in a tumor.

This recruitment of specific co-regulators to the ligand receptor complex depends on the ligand that binds to the ER, the ER isoform, and "cross-talk" with other growth factor pathways [38]. SRC-3 is known to be important as a co-activator in breast cancer. In tumors and cancer cell lines that are HER2-positive and resistant to endocrine therapy with tamoxifen, studies demonstrate that SRC- 3 is recruited to ER- $\alpha$, but not ER- $\beta$ in the presence of tamoxifen. In specimens from patients who were HER2-negative and sensitive to endocrine therapy with tamoxifen, estrogen recruited SRC-3 to both ER isoforms, but tamoxifen did not [42]. Finally, when SRC-3 was knocked down, there was reduced expression of the estrogen target gene, pS2 in MCF7 cells. After the SRC-3 knockdown in cells derived from HER2-positive tumors, there was a decrease in cell proliferation and the cells regressed in the presence of tamoxifen [42].

To summarize the molecular process thus far: once an SERM binds to the ER it causes a change in the shape of the ER. This change of shape allows recruitment of co-activators, if it is destined to elicit an estrogenic response, or co-repressors if its response is anti-estrogenic. The binding of the coregulatory molecules leads to the activation of the promoter sequence of the estrogenic responsive gene [36]. This process is also controlled by the degradation and disassembly of complexes at the gene promoter site, which causes renewed activation of the signal to initiate RNA synthesis. In this way the SERM can specifically modulate the estrogen responsiveness of a target tissue (See review Jordan [36]).

\section{Clinical relevance}

The full details of the mechanism of action of SERMs have yet to be precisely described however, their clinical importance as an advance in medicine is proven. Tamoxifen was initially tested in humans in the early $1970 \mathrm{~s}$, before extensive anti-tumor testing in animals [39], [40]. Animal testing [1], [9], [10] refocused efforts and targeted the ER [41], thereby opening the door for chemoprevention. Through animal studies tamoxifen was found to 
have targeted anti-tumor activity and initially, anti-estrogenic activity correlated with anti-tumor activity. These findings led to extensive human trials that helped consolidate the actions of SERMs and refined their applications. In initial human studies tamoxifen, an "antiestrogen", was found to lower bone density in pre-menopausal women [42]. However, the "estrogen-like" actions of tamoxifen, maintained bone density in post-menopausal women [43], [44]. In the uterus tamoxifen acts as an agonist and increases the risk of endometrial cancer in post-menopausal women [45]. The next sections review the large-scale human chemoprevention trials of SERMs.

\section{Chemoprevention}

The first large human trial involving tamoxifen was the Royal Marsden study performed by Powles and colleagues [46], [47]. For this study approximately 3000 high-risk women were recruited and randomized to receive treatment with tamoxifen $20 \mathrm{mg} /$ day for 8 years or placebo. High-risk status was determined by family history and a history of benign breast disease. The study found a decrease in LDL and loss of bone density in premenopausal women, but increased bone density in postmenopausal women and increased endometrial thickening on ultrasound study. Although this study initially showed no difference in the incidence of breast cancer, it was not powered to detect a difference in the development of breast cancer with either treatment group. Nevertheless, the twenty-year follow-up of this study does show a statistically significant reduction in the incidence of ER-positive breast cancer in the tamoxifen treatment arm after the 8 years of treatment [48].

The National Surgical Adjunctive Breast and Bowel Project (NSABP) P-1 trial by Bernard Fisher and colleagues was the first major chemoprevention trial in the Unites Stated with tamoxifen [49]. Over 13,000 women were recruited for this study in multiple centers around the US and Canada. Once again highrisk status was determined by family history, breast biopsy with pathological findings of lobular carcinoma in situ or atypical ductal hyperplasia, no children, menarche by 12 and age at birth of first child of over 30 . The initial results of the NSABP trial showed a $49 \%$ reduction in the risk of invasive breast cancer and a $50 \%$ reduction in the risk of non-invasive breast cancer. Tamoxifen also reduced the incidence of osteoporotic fractures. No difference was seen in the risk of myocardial infarction but there was an increased risk of deep venous thrombosis, endometrial cancer and cataracts in the tamoxifen group.

Based on these clinical trials in 1998, tamoxifen was approved by the US FDA for reduction of the risk of breast cancer in high-risk women. Despite the positive results of the NSABP P- 1 trial the side effects noted in the tamoxifen group resurrected the interest in other SERMs that had similar chemopreventive profiles to tamoxifen but with a more desirable side effect profile. This has led to human trials with raloxifene, an old compound, which had not been studied much since its discovery in the late $1970 \mathrm{~s}$ [50], [51].

\section{Prevention of osteoporosis}

In laboratory studies raloxifene was shown to inhibit DMBA-induced rat mammary carcinoma growth [52] and development [53], however, it was not as potent as tamoxifen. More importantly, raloxifene was as effective as tamoxifen in maintaining ovariectomized rat bone density but was less estrogen-like than tamoxifen in the rodent uterus [13] or in stimulating mouse endometrial tumor growth [54]. The short half-life of raloxifene makes it a difficult drug to dose, nonetheless; clinical trials with raloxifene have also helped define its pharmacology. The Multiple Outcomes for Raloxifene Evaluation (MORE) trial evaluated the effects of raloxifene in postmenopausal women [55], [60]. This study was extended to eight years as the Continuing Outcomes Relative to Evista (CORE) trial [61]. The results of the MORE/CORE trials demonstrated the effectiveness of raloxifene in preventing osteoporosis. In addition, raloxifene also inhibited the development of invasive breast cancer by $65 \%$ [61]. These clinical data justified the evaluation of raloxifene against tamoxifen to reduce the risk of breast cancer in high-risk postmenopausal women. The Study of Tamoxifen and Raloxifene (STAR) trial, was a phase III double-blinded study that randomized eligible postmenopausal women at a high risk for breast cancer, to receive tamoxifen $20 \mathrm{mg}$ daily or raloxifene $60 \mathrm{mg}$ daily [56]. The STAR trial demonstrated the equivalence of raloxifene and tamoxifen in reducing the incidence of invasive breast cancer. Furthermore, raloxifene had a better side effect profile with a lower incidence of endometrial cancer and hyperplasia, deep venous thromboses and cataracts. A drawback of raloxifene, however, was its decreased effectiveness in preventing the development of non-invasive breast cancer after two years, when compared to tamoxifen. Currently raloxifene is FDA-approved for the treatment and prevention of osteoporosis, and risk reduction for breast cancer in high-risk postmenopausal women.

\section{Extending chemoprevention}

The development of a chemopreventive agent such as tamoxifen but which has significant side effects had led to interest in whether naturally occurring compounds have similar chemopreventive effects. Epidemiologic observations have made this question even more seductive. While the etiology may be unclear, it has been well documented that Asian women have a lower incidence of breast and colorectal than Caucasian women [57]. Asian diets in particular are high in soy foods, which are felt to be responsible for this difference. When Asian women emigrate to western countries their incidence of breast cancer approaches that of the indigenous population [58]. This phenomenon has been observed in Japanese and Caucasian women who emigrate to the United States. It has also been observed that the risk of breast cancer in Asian Americans decreases in relation to increasing intake of soy derivatives [59]. Additionally, Chinese women who adopt a more westernized diet also appear to increase their incidence of breast cancer. All these findings have generated an interest in soy foods and its impact on hormone levels in the body. Phytoestrogens are the focus of current investigations. However, it should be stressed at the outset that despite beliefs of benefits from changes in diet and administration of supplements, there are dangers that breast cancer growth could be enhanced rather than prevented.

\section{What are Phytoestrogens?}

Phytoestrogens are plant derivatives that bear a structural similarity to 17-beta-estradiol and act in a similar manner. Structures of common phytoestrogens, SERMs and 17-beta-estradiol are shown in Fig. 3. The principal phytoestrogen groups are flavonoids, lignans, coumestans and stilbenes [60], [61], [62]. Phytoestrogens are present in common foods such as soybeans, grains, fruits and vegetables. An in-depth review of the various types of phytoestrogens is beyond the scope of this article, how- 
ever, common properties of most phytoestrogens include their metabolism by gut flora to additional derivatives with varying estrogenic activity. Many studies have focused on isoflavones, which are a subgroup of the flavonoids, they include but are not limited to genistein, daidzein and biochanin $A$. These isoflavones have varying estrogenic activity [63] and isoflavones have been proposed as natural SERMs. Studies show that isoflavones act as antioxidants in vitro and exert antiproliferative activities [64], [65]. Equol ( Fig.3), an estrogenic metabolite of the isoflavonoids family [66], is produced from daidzein by the action of intestinal flora. This metabolic conversion however occurs in only $30 \%$ of the population [67].

Lignans, the most prevalent phytoestrogens in the diet are found in whole wheat, fruits and vegetables. Lignans are metabolized by the action of gut microflora into enterolactones and enterodiol [60] with very weak estrogenic properties [66]. While there are many studies on isoflavones, there are significantly fewer studies on coumestans and stilbenes. Coumestans are potent activators of the ER signaling pathway but are not as prevalent in the diet. Resveratrol is the most common stilbene and its use as a chemopreventive agent against breast cancer is actively being studied in rodent models [60]. In the next section we will consider the mechanism of action of phytoestrogens. The interaction of phytoestrogens with ERs is in some ways similar to the SERM/ER interaction, but there are significant differences that confound biological comparisons.

\section{Mechanism of action of phytoestrogens}

Hydroxylated SERMs in general have a higher binding affinity for both ER $\alpha$ and $\mathrm{ER} \beta$ compared to phytoestrogens. As with SERMS, phytoestrogens can bind to either ER $\alpha$ or ER $\beta$ however, phytoestrogens appear to have a higher affinity for $\operatorname{ER} \beta$ [68]. This affinity may be dose-dependent but overall phytoestrogens have a significantly lower affinity for the ER than estradiol [69], [70]. In addition the estrogenic potency of phytoestrogens varies within the particular phytoestrogen group. For example, within the flavonoid family genistein has greater potency than biochanin A, which has greater potency than daidzein [63]. Kuiper and colleagues [31] demonstrated that the stimulation of transcriptional activity by both subtypes of the ER vary depending on the estrogenic potency of the phytoestrogen and the further use of reporter gene assays demonstrate that synthetic estrogens and phytoestrogens have varying affinity for the ER and for each ER isoforms [68].

SERMs are non-steroidal estrogens that become antiestrogenic by virtue of their correctly positioned side chain. However, the antiestrogen side chain is not present in phytoestrogens and this structural deficit may therefore limit their classifications as SERMs. Nevertheless, the presence of a correctly positioned phenolic ring and also the distance between the two opposing phenolic oxygens in the isoflavone structure is similar to that of 17beta-estradiol ( Fig. 3). This similarity allows the isoflavones to bind to either subtype of ER, effectively displacing 17-beta-estradiol. Studies have found that isoflavones have both agonistic and antagonistic effects, although they are strong ER $\beta$ agonists and weak ER $\alpha$ agonists [71]. It is this pharmacological receptor interaction rather than competitive interaction at a single receptor site that may be responsible for some of the diverse biological actions of phytoestrogens. This action may explain how phytoestrogens protect against breast cancer, because ER $\beta$ inhibits mammary cell growth as well as the stimulatory effects of ER $\alpha$ [72]. However, there is yet another dimension of molecular ac- tion at the ER that might be important. It is not certain whether isoflavones displace the estradiol by binding to a primary site on the ER, causing competitive binding between the isoflavones and the estradiol, or whether the isoflavones bind to a secondary site on the ER [73]. In contrast, genistein has been found to bind to the active site of $\operatorname{ER} \beta$ [74].

Recent studies have attempted to decipher the actual role of each receptor subtype in gene activation and physiological response. Part of the problem in determining the physiological actions of phytoestrogens is our ignorance of the actual role of the ER $\alpha$ and ER $\beta$. For example, a study by Hertrampf and colleagues [75] shows that the osteoprotective effect of genistein is mediated through the ER $\alpha$-dependent pathways and its effect is enhanced by physical activity. Also, the activation of ER $\beta$ may modulate ER $\alpha$-mediated physiological effects in vivo.

Many factors such as the ligand, dose and interaction of the ligand and receptor all influence ER molecular biology at the target site [76].

As with the SERMs, studies have shown that the recruitment of coregulatory molecules may be important in determining the function of phytoestrogens. In particular, isoflavones appear to selectively trigger ER $\beta$ transcriptional pathways, especially transcriptional repression. This affinity for the ER $\beta$ results in the exposure of a weak activation function-2 (AF-2) on the surface of $\mathrm{ER} \beta$, which has greater affinity for certain coregulators compared to $\operatorname{ER} \alpha$ [72]. Phytoestrogens also have differential activity on several ER associated signaling pathways. For example, Akt, which is normally phosphorylated secondary to activation of $\mathrm{ER} \alpha$, is up-regulated by genistein and daidzein in ER-positive breast cancer cell lines, while resveratrol has an inhibitory effect on the phosphorylation of Akt [77]. In contrast, in ER-negative cell lines, resveratrol and daidzein activate Akt and genistein inhibits activation of Akt [77]. This is clearly a non-ER event, but whether this is cancer-specific or a toxicity of studies conducted in vitro can only be resolved with studies in vivo.

Although the isoflavones have agonistic and antagonistic estrogenic effects, the phytoestrogens also induce differentiation as well as inhibit angiogenesis, cell proliferation, tyrosine kinase, and topoisomerase II; all of which will help prevent tumor growth. However, it is important to stress again that despite the fact that there have been numerous and extensive laboratory studies on the mechanisms of breast cancer chemoprevention with phytoestrogens, there is no definitive evidence that proves that phytoestrogens are chemopreventive but they may contribute to adverse outcomes in breast cancer [78].

Cell and animal studies on the effect of phytoestrogens Phytoestrogens have been likened to natural SERMs, and a brief survey of cell and animal studies of phytoestrogens reveals some similarities to SERMs such as tamoxifen. The approach to these studies may be classified into three broad categories. The first are studies that focus primarily on the role of phytoestrogens as a chemopreventive agent. The second are those studies that focus on phytoestrogens as a treatment agent. The third are those studies that focus on the biological effects when phytoestrogens are used continuously from neonates to adults.

The first category focuses on the chemopreventive effects of phytoestrogens in animal models that are subsequently treated with a chemical carcinogen. Animal studies have shown that when rats are treated with phytoestrogens and then exposed to a carcinogen they are less likely to develop breast cancer if exposure to phytoestrogens occurs at an early age [79], [80]. Lamarti- 
niere and colleagues [79] demonstrated that the timing of exposure to phytoestrogens whether pre- or post-puberty, may influence their action on preventing mammary carcinogenesis. Lamartiniere [79] found that neonatal injections of genistein reduced the incidence of DMBA-induced mammary tumors in rats. Further evaluation revealed that the overall effect of genistein on prepubertal rats appeared to be secondary to early differentiation in mammary tissues resulting in less active EGF signaling pathways in adulthood that may be protective against breast cancer. A recent meta-analyses by Warri et al. [81] revealed that pubertal exposure to phytoestrogens result in changes in the mammary gland morphology and signal pathways that mimic those induced by the estrogenic environment of early first pregnancy.

The second group of studies focus on the use of phytoestrogen treatments in both tumor-implanted athymic mice and breast cancer cell lines. Studies have shown that treating estrogen-sensitive MCF-7 cell lines with genistein has an inhibitory effect on their growth [82]. However, not all studies have had such conclusive findings such as that the action of phytoestrogens on breast cancer cells may be dose-dependent. At low concentrations phytoestrogens may stimulate growth, and at high concentrations inhibit growth [66], [82], [83], [84], [85]. The studies by Helferich help elucidate the dose-dependent actions of isoflavones [93], [86]. In animal studies, in which ovariectomized athymic mice were implanted with MCF-7 cells, genistein promotes the growth of ER+ MCF 7 cells and the effect of this isoflavone was dose-dependent. At concentrations as low as $10 \mathrm{nM}$ genistein promoted growth of ER-dependent MCF-7 cells in vitro [86]. At higher concentration (> 20 microM) genistein inhibited the MCF-7 cell growth. In addition genistein can stimulate growth of MCF-7 cells in vivo in a dose-dependent manner [87]. Clearly, these data call for caution with the use of phytoestrogens in women with breast cancer.

Indeed, the early study by Welshons et al. [66] cautioned against the use of antihormonal therapies that did not block the ER for the treatment of breast cancer because high fiber or exclusively vegetarian diets with phytoestrogens-containing food supplements could enhance the probability of tumor recurrence and growth. Furthermore the combination of phytoestrogens and tamoxifen to treat breast cancer may result in decreased efficacy of tamoxifen. In a study evaluating the development of tumor and the tumor latency period, tamoxifen-treated mice fed a low dose isoflavone-enriched diet had a higher tumor incidence and a shorter tumor latency period than placebo-treated mice [95]. In addition tamoxifen-associated mammary tumor prevention was also significantly reduced. Nevertheless, certain phytoestrogens have also been noted to cause apoptosis of human breast cancer cells and this occurred at concentrations of $20-25$ micromol/L [88], [89], [90]. While phytoestrogens have been observed to cause these various actions in vitro, it is unclear that in vivo the concentrations needed to achieve these actions are attainable. In animal studies a protective effect of phytoestrogens on the development of mammary cancer are conflicting [91], [92]. Santell and colleagues [92] have shown that while genistein may inhibit breast cancer cells in vitro, treatment of tumor-bearing athymic mice with genistein did not inhibit tumor growth, however in their study ER-negative human breast cancer cell lines were used. It would seem that the ability of phytoestrogens to be toxic in vitro at high concentrations does not extrapolate to models in vivo where the ability to maintain high local concentrations for long periods may be impaired.
A third approach is the study of the effects from early exposure to phytoestrogens from the perinatal periods and onwards. This approach was recently adopted by Mardon and colleagues [93]. Rats perinatally or lifelong exposed to a rich isoflavone diet exhibited higher body weight and fat mass at 24 months of age. Perinatal exposure to phytoestrogens led to higher bone mineral density in later life [93]. The translation of these data to human epidemiology and pharmacology is the challenge and has no immediate application to effects on mammary carcinogenesis. The observation is an estrogen-like action on bone rather than SERM related.

\section{Human trials}

Human trials on phytoestrogens differ from SERMs because unlike the SERMs, there are no major large-scale prospective studies of chemoprevention and pharmacology. Human studies on phytoestrogens can be divided into two broad categories. The first are studies that evaluate the effect of phytoestrogens on estrogen biosynthesis and excretion, the second are those studies that evaluate the overall impact of dietary phytoestrogens on specific clinical endpoints such as menopausal symptoms and bone mineral density presumably through a stimulatory action through the ER. Many studies have examined the use of phytoestrogens as chemopreventive agents; however, these studies are of limited value as they are retrospective.

\section{Estrogen biosynthesis and excretion}

Human studies on the effect of phytoestrogens on estrogen biosynthesis and excretion usually evaluate levels of circulating estrogen or steroid by-products and metabolites in the urine. In addition in many of these studies the levels of phytoestrogens are also measured and factors that affect these levels are explored. Human studies have shown conflicting results regarding the overall effect of phytoestrogens. Lu and colleagues [94] treated 10 pre-menopausal women with a soy-containing diet beginning on day two of the menstrual cycle to day two of the next cycle. Blood and urine samples were obtained before and during the initiation of the soy diet. Their results showed that the circulating levels of 17 -beta-estradiol decreased by $25 \%$, however, cycle length did not change [94]. A dietary intervention study by Kumar and co-workers showed similar findings [95]. This study randomized women to receive $40 \mathrm{mg}$ of isoflavones day or placebo for a 12 -week period. They found that serum free estradiol and estrone levels decreased. Serum hormone binding globulin increased and mean cycle length also increased. Conversely, a year-long dietary intervention study by Maskarinec and co-workers [96] in premenopausal women did not find any difference in cycle length or hormone levels. These studies raise the question that while dietary intake of phytoestrogens is important, intake alone may not be the determinant of a chemoprotective effect.

Since a Finnish case control study [97] suggests that high enterolactone concentrations are associated with decreased breast cancer risk., it is possible that lifestyle factors that affect enterolactone may be linked to breast cancer risk. Whether these lifestyle factors that control enterolactone levels are linked to breast cancer risk remains to be seen. Administration of antibiotics has been noted to decrease the serum concentration of enterolactone for a prolonged period [98]. Premenopausal women who are treated with long-term antibiotics for urinary tract infections seem to be at higher risk for breast cancer, presumably because it alters the gut metabolism of phytoestrogens [99]. Smoking and obesity have been noted to decrease plasma enterolac- 
tone levels, however, tea, coffee, fiber and vegetables have the opposite effect [100]. In a study monitoring plasma enterolactone levels, women were noted to have a higher plasma concentration while on wheat bread $41.1 \mathrm{nmol} / \mathrm{L}$ compared to $15.4 \mathrm{nmol} / \mathrm{L}$ while on white bread [67]. Links to actual cancer risk do not exist but associations have been noted.

In human studies, it is often difficult to measure serum levels of phytoestrogens, because of a short half-life. Since most phytoestrogens are excreted in the urine, urine analysis of metabolites of phytoestrogens can be used to give an indication of exposure to phytoestrogens [101]. Urinary excretion of phytoestrogens varies in different regions of the world [102]. Women in areas with a low incidence of breast cancer have higher urinary isoflavonoids than women living in areas with a high incidence of breast cancer. Vegetarians also have a higher concentration of isoflavonoids in their urine than omnivores [103]. The excretion of equol in the urine has been proposed as a possible marker of the chemoprotective effect of phytoestrogens [112], [113]. Duncan and colleagues [104] studied the hormone profile of equol excretors versus equol non-excretors and found that regardless of the amount of phytoestrogens ingested in the diet, equol excretors had decreased levels of estrone, estrone sulfate, testosterone, DHEA and higher levels of steroid hormone binding globulin. This steroid hormone profile has been found to be a protective profile for breast cancer. The possible mechanisms to create a "change profile" may include the findings that phytoestrogens stimulate the production of sex steroid binding globulin by liver cells [103] and have inhibitory effects on the enzymes involved in the synthesis of estrogen. Phytoestrogens are known to decrease the conversion of androgens to estrogen by blocking the aromatase enzyme system. [105].

\section{Phytoestrogens and cinical endpoints}

The second group of human studies are those that focus on the effect of phytoestrogens on focal clinical endpoints. These endpoints vary and include alleviation of menopausal symptoms, maintenance of bone mineral density and development of breast cancer in some retrospective studies. Given recent concern regarding the possible adverse effects of hormone replacement therapy other alternatives for treatment of menopausal symptoms have been explored and phytoestrogens have played a significant role. A recent Cochrane review of the database revealed no clear evidence of the effectiveness of phytoestrogens in alleviating menopausal symptoms [106]. This notwithstanding, there are some small trials which show a benefit to using phytoestrogens for treating menopausal symptoms. In a doubleblind prospective study sixty women were randomized to receive $60 \mathrm{mg}$ of isoflavones daily for 3 months or placebo [107]. The menopausal symptoms before and after treatment were recorded. Women receiving the phytoestrogens treatment noted a $57 \%$ and $43 \%$ decrease in the incidence of hot flashes and night sweats, respectively. Similar results were seen in a small trial using a 6-week treatment of flaxseed for the treatment of menopausal symptoms [108]. Some investigators are evaluating the use of phytoestrogens as alternative agents to hormone replacement therapy (HRT) in the management of postmenopausal symptoms [107]. Recently, prenylated flavonoids derived from hops are being used to treat menopausal symptoms. One such compound is 8-prenylnaringenin ( $\bullet$ Fig. 3 ) that has strong estrogenic activity [109]. MenoHop an agent containing the phytoestrogen 8-prenylnaringenin, is currently being evaluated to treat menopausal complaints in Belgium [110].
The relationship between phytoestrogens and bone health remains unclear, with some studies showing a benefit associated with phytoestrogen treatment and others showing none [111]. Supplementation of diet with isoflavones has been shown to help maintain lumbar spine bone density [122], [112]. A randomized double-blind control trial was performed to compare with HRT, the effect of the phytoestrogen genistein on bone metabolism and bone mineral density [113]. Patients were randomized to receive either HRT daily ( $1 \mathrm{mg}$ of 17-beta-estradiol and $0.5 \mathrm{mg}$ norethisterone) or genistein $30 \mathrm{mg}$ daily or placebo daily for a period of 1 year. On completion of this protocol women receiving the HRT and genistein had significantly increased bone mineral density in the femur compared to those in the placebo group. In another randomized control trial, Atkinson and colleagues [114] showed that women receiving an isoflavones extract had a decreased loss of lumbar spine bone mineral content and bone mineral density compared to placebo.

Direct studies on the efficacy of phytoestrogens in preventing breast cancer are difficult given the length of time required to perform such a study. Indeed, this obstacle with phytoestrogen research illustrates how powerful SERMS are to produce dramatic decreases in breast cancer incidence within 5-10 years [55], [115]. However, surrogate endpoints such as the effect of phytoestrogens on breast cell proliferation and mammographic density have been studied. Increased breast cell proliferation and increased mammographic density are risk factors for malignancy. Short-term dietary supplementation with phytoestrogens stimulates breast epithelial proliferation [116]. This finding has also been noted in premenopausal women treated with prolonged phytoestrogen intake [117]. This breast proliferation is evident on mammograms as increased mammographic densities and some of these parenchymal patterns are associated with a higher risk of breast cancer [118]. These histological findings are supported by the observation of increased high risk parenchymal sonographic patterns in women who report low dietary soy protein intake [119]. Other studies such as that by Maskarinec and colleagues [120] show a similar finding in mammographic density in women treated with prolonged phytoestrogen supplementation.

As noted in animal studies, [101] the age at which a woman is exposed to phytoestrogens and length of exposure to phytoestrogens may be important in determining whether a protective benefit is obtained. A prospective 12-ear study of diet and breast cancer by Key and colleagues [121] of over 30,000 women in Japan showed that there was no relationship found between soy food consumption and the development of breast cancer, however this study was comprised of mostly non-adolescent women. In contrast, Shu and colleagues [122] performed a retrospective case controlled study on Chinese women with breast cancer. Subjects completed a questionnaire regarding their dietary intake in adolescence. A high soy consumption as an adolescent was associated with a decreased incidence of breast cancer as an adult. This may also explain why when women emigrate to countries with a higher incidence of breast cancer than their native country, they are more likely to have a decreased incidence of breast cancer if they emigrated after puberty [123].

While there is increasing excitement at the possible role of phytoestrogens as chemopreventive agents or as complimentary alternative medicine for menopausal symptoms their safety profile remains largely unknown and concerns regarding this have been raised in two recent reviews [124], [125]. Isoflavones such as genistein have been found to stimulate the growth of MCF-7 cells [86], [93]. Some studies have shown that soy products in- 
crease breast epithelial cell proliferation [125], [126], which may increase the risk of breast cancer. These findings suggest caution in the broad use of phytoestrogens. In addition the interaction of phytoestrogens and tamoxifen inbreast cancer patients may negate the protective effects of SERMs and caution has een advised against thebination of these two agents [126].

\section{Conclusion}

\section{$\nabla$}

Since their discovery the use of SERMs in clinical practice continues to expand [127], [128], [129]. As our knowledge of phytoestrogens grows, so does our understanding of their interaction with the ER and ability to possibly act as a natural SERM or conversely to antagonize the actions of SERMs. However, based on their structure-function relationships, the molecular endocrinology of SERMs and phytoestrogens is very different and the phytoestrogens appear to act as ER agonists at low concentrations but may act as antagonists by biochemical mechanisms through the ER beta receptor complex. Despite the advances in the treatment of breast cancer, prevention if possible must be superior to treatment. Currently tamoxifen and raloxifene are the first important steps in the quest to develop a complete preventative agent. In the future, a role, if any for the phytoestrogens or their derivatives may emerge, but current research is too weak to provide any clinical guidelines beyond caution. Alternatively, clues from laboratory studies may prove to be important in future drug development. An example of this is the current interest in the pharmacology of resveratrol which may have valuable pharmacological actions not mediated via the ER [130], [131].

\section{Acknowledgements}

Supported by the following grants: 5T32CA10365-03 (R.R.P) and by the Department of Defense Breast Program under award number BC050277 Center of Excellence (Views and opinions of, and endorsements by the author(s) do not reflect those of the US Army or the Department of Defense) (VCJ), SPORE in Breast Cancer CA 89018 (VCJ), R01 GM067156 (VCJ), FCCC Core Grant NIH P30 CA006927 (VCJ), the Genuardi Fund, the Avon Foundation and the Weg Fund of Fox Chase Cancer Center (VCJ).

\section{References}

1 Jordan VC. Tamoxifen: a most unlikely pioneering medicine. Nat Rev Drug Discov 2003; 2: 205-13

2 Beatson GT. On the treatment of inoperable cases of carcinoma of the mamma: suggestions for a new method of treatment with illustrative cases. Lancet 1896; 2 : $104-7$

3 Boyd S. On oophorectomy in cancer of the breast. B M J 1900; ii: 1161 -7

4 Allen E, Doisy EA. An ovarian hormone: Preliminary reports on its localization, extraction and partial purification and action in test animals. JAMA 1923; 81: 810-21

5 Lacassagne A. Hormonal pathogenesis of adenocarcinoma of the breast. Am J Cancer 1936; 27: 217 -25

6 Jensen EV, Jacobson HI. Basic guides to the mechanism of estrogen action. Recent Prog Horm Res 1962; 18: 387-414

7 Jensen $E V$, Jordan $V C$. The estrogen receptor: a model for molecular medicine. Clin Cancer Res 2003; 9: 1980-9

8 Lippman ME, Bolan G. Oestrogen-responsive human breast cancer in long term tissue culture. Nature 1975; 256: $592-3$

9 Jordan VC. Antitumour activity of the antioestrogen ICI 46,474 (tamoxifen) in the dimethylbenzanthracene (DMBA)-induced rat mammary carcinoma model. J Steroid Biochem 1974; 5: 354
10 Jordan VC. Effect of tamoxifen (ICI 46,474) on initiation and growth of DMBA-induced rat mammary carcinomata. Eur J Cancer 1976; 12 : 419-24

11 Harper MJ, Walpole AL. A new derivative of triphenylethylene: effect on implantation and mode of action in rats. J Reprod Fertil 1967; 13: $101-19$

12 Jordan VC, Robinson SP. Species-specific pharmacology of antiestrogens: role of metabolism. Fed Proc 1987; 46: 1870-4

13 Jordan VC, Phelps E, Lindgren JU. Effects of anti-estrogens on bone in castrated and intact female rats. Breast Cancer Res Treat 1987; 10: 31 -5

14 Jordan VC. Selective estrogen receptor modulation: a personal perspective. Cancer Res 2001; 61: 5683-7

15 Smith CL, O'Malley BW. Coregulator function: a key to understanding tissue specificity of selective receptor modulators. Endocr Rev 2004; 25: $45-71$

16 Jordan VC, Collins MM, Rowsby L, Prestwich G. A monohydroxylated metabolite of tamoxifen with potent antioestrogenic activity. J Endocrinol 1977; 75: 305-16

17 Allen KE, Clark ER, Jordan VC. Evidence for the metabolic activation of non-steroidal antioestrogens: a study of structure-activity relationships. Br J Pharmacol 1980; 71: 83 - 91

18 Borgna JL, Rochefort $H$. Hydroxylated metabolites of tamoxifen are formed in vivo and bound to estrogen receptor in target tissues. J Biol Chem 1981; 256: 859-68

19 Lien EA, Solheim E, Ueland PM. Distribution of tamoxifen and its metabolites in rate and human tissues during steady-state treatment. Cancer Res 1991; 51: 4837-44

20 Lien EA, Solheim E, Kvinnsland S, Ueland PM. Identification of 4-hydroxy- $N$-desmethyltamoxifen as a metabolite of tamoxifen in human bile. Cancer Res 1988; 48: 2304-8

21 Lien EA, Solheim E, Lea OA, Lundgren S, Kvinnsland S, Ueland PM. Distribution of 4-hydroxy- $N$-desmethyltamoxifen and other tamoxifen metabolites in human biological fluids during tamoxifen treatment. Cancer Res 1989; 49: 2175-83

22 Jordan VC. New insights into the metabolism of tamoxifen and its role in the treatment and prevention of breast cancer. Steroids 2007; 72 : $829-42$

23 Fromson JM, Pearson S, Bramah S. The metabolism of tamoxifen (I.C. I. 46,474). II. In female patients. Xenobiotica 1973; 3: $711-4$

24 Fromson JM, Pearson S, Bramah S. The metabolism of tamoxifen (I.C. I. 46,474). I. In laboratory animals. Xenobiotica 1973; 3: 693 - 709

25 Borges S, Desta Z, Li L, Skaar TC, Ward BA, Nguyen A et al. Quantitative effect of CYP2D6 genotype and inhibitors on tamoxifen metabolism: implication for optimization of breast cancer treatment. Clin Pharmacol Ther 2006; 80: 61 - 74

$26 \mathrm{Kemp} D C$, Fan PW, Stevens JC. Characterization of raloxifene glucuronidation in vitro: contribution of intestinal metabolism to presystemic clearance. Drug Metab Dispos 2002; 30: 694-700

27 Jeong EJ, Liu Y, Lin H, Hu M. Species- and disposition model-dependent metabolism of raloxifene in gut and liver: role of UGT1A10. Drug Metab Dispos 2005; 33: 785 - 94

28 Snyder KR, Sparano N, Malinowski JM. Raloxifene hydrochloride. Am J Health Syst Pharm 2000; 76-8: 1669-75

29 Buzdar AU, Marcus C, Holmes F, Hug V, Hortobagyi G. Phase II evaluation of Ly156758 in metastatic breast cancer. Oncology 1988; 45: $344-5$

30 Kuiper GG, Enmark E, Pelto-Huikko M, Nilsson S, Gustafsson JA. Cloning of a novel receptor expressed in rat prostate and ovary. Proc Natl Acad Sci U S A 1996; 93: 5925 - 30

31 Kuiper GG, Carlsson B, Grandien K, Enmark E, Haggblad J, Nilsson S et al. Comparison of the ligand binding specificity and transcript tissue distribution of estrogen receptors alpha and beta. Endocrinology 1997; 138: $863-70$

32 Lim YC, Li L, Desta Z, Zhao Q Rae JM, Flockhart DA et al. Endoxifen, a secondary metabolite of tamoxifen, and 4-OH-tamoxifen induce similar changes in global gene expression patterns in MCF-7 breast cancer cells. J Pharmacol Exp Ther 2006; 318: 503-12

33 Koehler KF, Helguero LA, Haldosen LA, Warner M, Gustafsson JA. Reflections on the discovery and significance of estrogen receptor beta. Endocr Rev 2005; 26: $465-78$

34 Chang EC, Frasor J, Komm B, Katzenellenbogen BS. Impact of estrogen receptor beta on gene networks regulated by estrogen receptor alpha in breast cancer cells. Endocrinology 2006; 147: 4831 - 42

35 Strom A, Hartman J, Foster JS, Kietz S, Wimalasena J, Gustafsson JA. Estrogen receptor beta inhibits 17-beta-estradiol-stimulated prolifera- 
tion of the breast cancer cell line T47D. Proc Natl Acad Sci U S A 2004; 101: $1566-71$

36 Jordan VC. Chemoprevention of breast cancer with selective oestrogen-receptor modulators. Nat Rev Cancer 2007; 7: 46-53

37 Paige LA, Christensen DJ, Gron H, Norris JD, Gottlin EB, Padilla KM et al. Estrogen receptor (ER) modulators each induce distinct conformational changes in ER alpha and ER beta. Proc Natl Acad Sci U S A 1999; 96: 3999-4004

38 Mc Ilroy M, Fleming FJ, Buggy Y, Hill AD, Young LS. Tamoxifen-induced ER-alpha-SRC-3 interaction in HER2 positive human breast cancer; a possible mechanism for ER isoform specific recurrence. Endocr Relat Cancer 2006; 13: 1135 - 45

39 Cole MP, Jones CT, Todd ID. A new anti-oestrogenic agent in late breast cancer. An early clinical appraisal of ICI46474. Br J Cancer 1971; 25: $270-5$

40 Ward HW. Anti-oestrogen therapy for breast cancer: a trial of tamoxifen at two dose levels. Br Med J 1973; 1: 13 - 4

41 Jordan VC, Koerner S. Tamoxifen (ICI 46,474) and the human carcinoma 8S oestrogen receptor. Eur J Cancer 1975; 11: 205 -6

42 Powles TJ, Hickish T, Kanis JA, Tidy A, Ashley S. Effect of tamoxifen on bone mineral density measured by dual-energy x-ray absorptiometry in healthy premenopausal and postmenopausal women. J Clin Oncol 1996; $14: 78-84$

43 Kristensen B, Ejlertsen B, Dalgaard P, Larsen L, Holmegaard SN, Transbol I et al. Tamoxifen and bone metabolism in postmenopausal low-risk breast cancer patients: a randomized study. J Clin Oncol 1994; 12: $992-7$

44 Love RR, Mazess RB, Barden HS, Epstein S, Newcomb PA, Jordan VC et al. Effects of tamoxifen on bone mineral density in postmenopausal women with breast cancer. N Engl J Med 1992; 326: 852 - 6

45 Jordan VC, Morrow M. Should clinicians be concerned about the carcinogenic potential of tamoxifen? Eur J Cancer 1994; 30A: 1714-21

46 Powles TJ, Hardy JR, Ashley SE, Farrington GM, Cosgrove D, Davey JB et al. A pilot trial to evaluate the acute toxicity and feasibility of tamoxifen for prevention of breast cancer. Br J Cancer 1989; 60: 126 - 31

47 Powles TJ, Jones AL, Ashley SE, O'Brien ME, Tidy VA, Treleavan J et al. The Royal Marsden Hospital pilot tamoxifen chemoprevention trial. Breast Cancer Res Treat 1994; 31: 73-82

48 Powles TJ, Ashley S, Tidy A, Smith IE, Dowsett M. Twenty-year follow-up of the Royal Marsden randomized, double-blinded tamoxifen breast cancer prevention trial. J Natl Cancer Inst 2007; 99: 283-90

49 Fisher B, Costantino JP, Wickerham DL, Redmond CK, Kavanah M, Cronin WM et al. Tamoxifen for prevention of breast cancer: report of the $\mathrm{Na}-$ tional Surgical Adjuvant Breast and Bowel Project P-1 Study. J Natl Cancer Inst 1998; 90: 1371 - 88

50 Lewis-Wambi JS, Jordan VC. Case histories: raloxifene. In: Taylor J, Triggle D, editors. Comprehensive medicinal chemistry II, Vol. 8. Oxford, UK: Elsevier Limited; 2006: 103-21

51 Black LJ, Jones CD, Falcone JF. Antagonism of estrogen action with a new benzothiophene derived antiestrogen. Life Sci 1983; 32: 1031-6

52 Clemens JA, Bennett DR, Black LJ, Jones CD. Effects of a new antiestrogen, keoxifene (LY156758), on growth of carcinogen-induced mammary tumors and on LH and prolactin levels. Life Sci 1983; 32: $2869-75$

53 Gottardis MM, Jordan VC. Antitumor actions of keoxifene and tamoxifen in the $N$-nitrosomethylurea-induced rat mammary carcinoma model. Cancer Res 1987; 47: 4020-4

54 Gottardis MM, Ricchio ME, Satyaswaroop PG, Jordan VC. Effect of steroidal and nonsteroidal antiestrogens on the growth of a tamoxifenstimulated human endometrial carcinoma (EnCa101) in athymic mice. Cancer Res 1990; 50: 3189-92

55 Cummings SR, Eckert S, Krueger KA, Grady D, Powles TJ, Cauley JA et al. The effect of raloxifene on risk of breast cancer in postmenopausal women: results from the MORE randomized trial. Multiple outcomes of raloxifene evaluation. JAMA 1999; 281: 2189-97

56 Vogel VG, Costantino JP. Wickerham DL, Cronin WM, Cecchini RS, Atkins $J N$ et al. Effects of tamoxifen vs raloxifene on the risk of developing invasive breast cancer and other disease outcomes: the NSABP study of tamoxifen and raloxifene (STAR) P-2 trial. JAMA 2006; 295: 2727-41

57 Fund WCR. Food, nutrition and the prevention of cancer: a global perspective. Washington: American Institute for Cancer Research; 1997

58 Wu AH, Ziegler RG, Nomura AM, West DW, Kolonel LN, Horn-Ross PL et al. Soy intake and risk of breast cancer in Asians and Asian Americans. Am J Clin Nutr 1998; 68: 1437S - 43S
59 Wu AH, Ziegler RG, Horn-Ross PL, Nomura AM, West DW, Kolonel LN et $a l$. Tofu and risk of breast cancer in Asian-Americans. Cancer Epidemiol Biomarkers Prev 1996; 5: 901 -6

60 Limer JL, Speirs V. Phyto-oestrogens and breast cancer chemoprevention. Breast Cancer Res 2004; 6: 119-27

61 Moon YJ, Wang X, Morris ME. Dietary flavonoids: effects on xenobiotic and carcinogen metabolism. Toxicol In Vitro 2006; 20: 187-210

62 Sirtori CR, Arnoldi A, Johnson SK. Phytoestrogens: end of a tale? Ann Med 2005; 37: 423-38

63 Zand RS, Jenkins DJ, Diamandis EP. Steroid hormone activity of flavonoids and related compounds. Breast Cancer Res Treat 2000; 62: 35 - 49

64 Peterson $\mathrm{G}$. Evaluation of the biochemical targets of genistein in tumor cells. J Nutr 1995; 125: 784S-9S

65 Fotsis T, Pepper M, Adlercreutz H, Fleischmann G, Hase T, Montesano R et al. Genistein, a dietary-derived inhibitor of in vitro angiogenesis. Proc Natl Acad Sci U S A 1993; 90: 2690-4

66 Welshons WV, Murphy CS, Koch R, Calaf G, Jordan VC. Stimulation of breast cancer cells in vitro by the environmental estrogen enterolactone and the phytoestrogen equol. Breast Cancer Res Treat 1987; 10: 169-75

67 Adlercreutz H. Phyto-oestrogens and cancer. Lancet Oncol 2002; 3 . $364-73$

68 Kuiper GG, Lemmen JG, Carlsson B, Corton JC, Safe SH, van der Saag PT et al. Interaction of estrogenic chemicals and phytoestrogens with estrogen receptor beta. Endocrinology 1998; 139: 4252 -63

69 McCarty MF. Isoflavones made simple - genistein's agonist activity for the beta-type estrogen receptor mediates their health benefits. Med Hypotheses 2006; 66: 1093 - 114

70 van der Woude H, Ter Veld MG, Jacobs N, van der Saag PT, Murk AJ, Rietjens IM. The stimulation of cell proliferation by quercetin is mediated by the estrogen receptor. Mol Nutr Food Res 2005; 49: 763-71

71 Fitzpatrick LA. Phytoestrogens - mechanism of action and effect on bone markers and bone mineral density. Endocrinol Metab Clin North Am 2003; 32: 233-52, viii

72 An J, Tzagarakis-Foster C, Scharschmidt TC, Lomri N, Leitman DC. Estrogen receptor beta-selective transcriptional activity and recruitment of coregulators by phytoestrogens. J Biol Chem 2001; 276: 17808 - 14

73 Martin PM, Horwitz KB, Ryan DS, McGuire WL. Phytoestrogen interaction with estrogen receptors in human breast cancer cells. Endocrinology 1978; 103: 1860 - 7

74 Pike AC, Brzozowski AM, Hubbard RE, Bonn T, Thorsell AG, Engstrom O et al. Structure of the ligand-binding domain of oestrogen receptor beta in the presence of a partial agonist and a full antagonist. EMBO J 1999; 18: $4608-18$

75 Hertrampf T, Gruca MJ, Seibel J, Laudenbach U, Fritzemeier KH, Diel P. The bone-protective effect of the phytoestrogen genistein is mediated via ER alpha-dependent mechanisms and strongly enhanced by physical activity. Bone 2007; 40: 1529-35

76 Chang EC, Charn TH, Park SH, Helferich WG, Komm B, Katzenellenbogen $J A$ et al. Estrogen receptors alpha and beta as determinants of gene expression: influence of ligand, dose, and chromatin binding. Mol Endocrinol 2008; 22: $1032-43$

77 Brownson DM, Azios NG, Fuqua BK, Dharmawardhane SF, Mabry TJ. Flavonoid effects relevant to cancer. J Nutr 2002; 132: 3482S - 9S

78 Mense SM, Hei TK, Ganju RK, Bhat HK. Phytoestrogens and breast cancer prevention: possible mechanisms of action. Environ Health Perspect 2008; $116: 426-33$

79 Lamartiniere CA, Moore JB, Brown NM, Thompson R, Hardin MJ, Barnes $S$. Genistein suppresses mammary cancer in rats. Carcinogenesis 1995; $16: 2833-40$

80 Murrill WB, Brown NM, Zhang JX, Manzolillo PA, Barnes S. Molecular epidemiology and cancer prevention: Prepubertal genistein exposure suppresses mammary cancer and enhances gland differentiation in rats. Carcinogenesis 1996; 17: 1451 - 7

81 Warri A, Saarinen NM, Makela S, Hilakivi-Clarke L. The role of early life genistein exposures in modifying breast cancer risk. Br J Cancer 2008; 98: $1485-93$

82 Fioravanti L, Cappelletti V, Miodini P, Ronchi E, Brivio M, Di Fronzo G. Genistein in the control of breast cancer cell growth: insights into the mechanism of action in vitro. Cancer Lett 1998; 130: 143-52

83 Constantinou AI, Krygier AE, Mehta RR. Genistein induces maturation of cultured human breast cancer cells and prevents tumor growth in nude mice. Am J Clin Nutr 1998; 68: 1426S - 30S

84 Hsu JT, Hung HC, Chen CJ, Hsu WL, Ying C. Effects of the dietary phytoestrogen biochanin A on cell growth in the mammary carcinoma cell line MCF-7. J Nutr Biochem 1999; 10: 510-7 
85 Maggiolini M, Bonofiglio D, Marsico S, Panno ML, Cenni B, Picard D et al. Estrogen receptor alpha mediates the proliferative but not the cytotoxic dose-dependent effects of two major phytoestrogens on human breast cancer cells. Mol Pharmacol 2001; 60: 595-602

86 Hsieh CY, Santell RC, Haslam SZ, Helferich WG. Estrogenic effects of genistein on the growth of estrogen receptor-positive human breast cancer (MCF-7) cells in vitro and in vivo. Cancer Res 1998; 58: 3833 -8

87 Allred CD, Allred KF, Ju YH, Goeppinger TS, Doerge DR, Helferich WG. Soy processing influences growth of estrogen-dependent breast cancer tumors. Carcinogenesis 2004; 25: 1649-57

88 Katdare $M$, Osborne M, Telang NT. Soy isoflavone genistein modulates cell cycle progression and induces apoptosis in HER-2/neu oncogene expressing human breast epithelial cells. Int J Oncol 2002; 21: 809-15

89 Leung LK, Wang TT. Bcl-2 is not reduced in the death of MCF-7 cells at low genistein concentration. J Nutr 2000; 130: 2922 -6

90 Vergote D, Cren-Olive C, Chopin V, Toillon RA, Rolando C, Hondermarck $H$ et al. (-)-Epigallocatechin (EGC) of green tea induces apoptosis of human breast cancer cells but not of their normal counterparts. Breast Cancer Res Treat 2002; 76: 195 - 201

91 Lamartiniere CA. Protection against breast cancer with genistein: a component of soy. Am J Clin Nutr 2000; 71: 1705S-7

92 Santell RC, Kieu N, Helferich WG. Genistein inhibits growth ofindependent human breast cancer cells in culture but not in athymic mice. J Nutr 2000; 130: 1665 -9

93 Mardon J, Mathey J, Kati-Coulibaly S, Puel C, Davicco MJ, Lebecque P et al. Influence of lifelong soy isoflavones consumption on bone mass in the rat. Exp Biol Med (Maywood) 2008; 233: 229-37

94 Lu L-JW, Anderson KE, Grady JJ, Kohen F, Nagamani M. Decreased ovarian hormones during a soya diet: implications for breast cancer prevention. Cancer Res 2000; 60: 4112 - 21

95 Kumar NB, Cantor A, Allen K, Riccardi D, Cox CE. The specific role of isoflavones on estrogen metabolism in premenopausal women. Cancer 2002; 94: $1166-74$

96 Maskarinec G, Williams AE, Inouye JS, Stanczyk FZ, Franke AA. A randomized isoflavone intervention among premenopausal women. Cancer Epidemiol Biomarkers Prev 2002; 11: 195 - 201

97 Pietinen P, Stumpf K, Mannisto S, Kataja V, Uusitupa M, Adlercreutz H. Serum enterolactone and risk of breast cancer: a case-control study in eastern Finland. Cancer Epidemiol Biomarkers Prev 2001; 10: 339-44

98 Kilkkinen A, Pietinen P, Klaukka T, Virtamo J, Korhonen P, Adlercreutz H. Use of oral antimicrobials decreases serum enterolactone concentration. Am J Epidemiol 2002; 155: 472 - 7

99 Knekt P, Adlercreutz H, Rissanen H, Aromaa A, Teppo L, Heliovaara M. Does antibacterial treatment for urinary tract infection contribute to the risk of breast cancer? Br J Cancer 2000; 82: 1107-10

100 Kilkkinen A, Stumpf $K$, Pietinen P, Valsta LM, Tapanainen $H$, Adlercreutz $\mathrm{H}$. Determinants of serum enterolactone concentration. Am J Clin Nutr 2001; 73: 1094 - 100

101 Valentin-Blasini L, Blount BC, Caudill SP, Needham LL. Urinary and serum concentrations of seven phytoestrogens in a human reference population subset. J Expo Anal Environ Epidemiol 2003; 13: 276 - 82

102 Peeters PH, Keinan-Boker L, van der Schouw YT, Grobbee DE. Phytoestrogens and breast cancer risk. Review of the epidemiological evidence. Breast Cancer Res Treat 2003; 77: 171 -83

103 Adlercreutz H. Human health and phytoestrogens. In: Korach K, editor. Reproductive and developmental toxicology. New York: Marcel Dekker Inc; 1998: 299-371

104 Duncan AM, Merz-Demlow BE, Xu X, Phipps WR, Kurzer MS. Premenopausal equol excretors show plasma hormone profiles associated with lowered risk of breast cancer. Cancer Epidemiol Biomarkers Prev 2000; 9: $581-6$

105 Whitehead SA, Lacey M. Phytoestrogens inhibit aromatase but not 17beta-hydroxysteroid dehydrogenase (HSD) type 1 in human granulosa-luteal cells: evidence for FSH induction of 17beta-HSD. Hum Reprod 2003; 18: 487-94

106 Lethaby AE, Brown J, Marjoribanks J, Kronenberg F, Roberts H, Eden J. Phytoestrogens for vasomotor menopausal symptoms. Cochrane Database Syst Rev; 2007: CD001395

107 Cheng G, Wilczek B, Warner M, Gustafsson JA, Landgren BM. Isoflavone treatment for acute menopausal symptoms. Menopause 2007; 14: $468-73$
108 Pruthi S, Thompson SL, Novotny PJ, Barton DL, Kottschade LA, Tan AD et al. Pilot evaluation of flaxseed for the management of hot flashes. J Soc Integr Oncol 2007; 5: 106-12

109 Gerhäuser C. Beer constituents as potential cancer chemopreventive agents. Eur J Cancer 2005; 41: 1941 - 54

110 Heyerick A, Vervarcke S, Depypere H, Bracke M, De Keukeleire D. A first prospective, randomized, double-blind, placebo-controlled study on the use of a standardized hop extract to alleviate menopausal discomforts. Maturitas 2006; 54: $164-75$

111 Weaver CM, Cheong JM. Soy isoflavones and bone health: the relationship is still unclear. J Nutr 2005; 135: $1243-7$

112 Alekel DL, Germain AS, Peterson CT, Hanson KB, Stewart JW, Toda T. Isoflavone-rich soy protein isolate attenuates bone loss in the lumbar spine of perimenopausal women. Am J Clin Nutr 2000; 72: 844-52

113 Morabito N, Crisafulli A, Vergara C, Gaudio A, Lasco A, Frisina N et al. Effects of genistein and hormone-replacement therapy on bone loss in early postmenopausal women: a randomized double-blind placebo-controlled study. J Bone Miner Res 2002; 17: 1904-12

114 Atkinson C, Compston JE, Day NE, Dowsett M, Bingham SA. The effects of phytoestrogen isoflavones on bone density in women: a double-blind, randomized, placebo-controlled trial. Am J Clin Nutr 2004; 79: 326 - 33

115 Fisher B, Costantino JP, Wickerham DL, Cecchini RS, Cronin WM Robidoux A et al. Tamoxifen for the prevention of breast cancer: current status of the National Surgical Adjuvant Breast and Bowel Project P-1 study. J Natl Cancer Inst 2005; 97: 1652 - 62

116 McMichael-Phillips DF, Harding C, Morton M, Roberts SA, Howell A, Potten CS et al. Effects of soy-protein supplementation on epithelial proliferation in the histologically normal human breast. Am J Clin Nutr 1998; 68: 1431S-5S

117 Petrakis NL, Barnes S, King EB, Lowenstein J, Wiencke J, Lee MM et al. Stimulatory influence of soy protein isolate on breast secretion in pre- and postmenopausal women. Cancer Epidemiol Biomarkers Prev 1996; 5: 785-94

118 Warner E, Lockwood G, Tritchler D, Boyd NF. The risk of breast cancer associated with mammographic parenchymal patterns: a meta-analysis of the published literature to examine the effect of method of classification. Cancer Detect Prev 1992; 16: 67 - 72

119 Jakes RW, Duffy SW, $\mathrm{Ng} F C$, Gao F, Ng EH, Seow A et al. Mammographic parenchymal patterns and self-reported soy intake in Singapore Chinese women. Cancer Epidemiol Biomarkers Prev 2002; 11: 608 - 13

120 Maskarinec G, Williams AE, Carlin L. Mammographic densities in a one-year isoflavone intervention. Eur J Cancer Prev 2003; 12: 165-9

121 Key TJ, Sharp GB, Appleby PN, Beral V, Goodman MT, Soda M et al. Soya foods and breast cancer risk: a prospective study in Hiroshima and Nagasaki, Japan. Br J Cancer 1999; 81: 1248 - 56

122 Shu XO, Jin F, Dai Q Wen W, Potter JD, Kushi LH et al. Soyfood intake during adolescence and subsequent risk of breast cancer among Chinese women. Cancer Epidemiol Biomarkers Prev 2001; 10: 483-8

123 Ziegler RG, Hoover RN, Pike MC, Hildesheim A, Nomura AM, West DW et al. Migration patterns and breast cancer risk in Asian-American women. J Natl Cancer Inst 1993; 85: 1819-27

124 Duffy C, Perez K, Partridge A. Implications of phytoestrogen intake for breast cancer. CA Cancer J Clin 2007; 57: 260 - 77

125 Rice S, Whitehead SA. Phytoestrogens and breast cancer - promoters or protectors? Endocr Relat Cancer 2006; 13: 995 - 1015

126 This P, De La Rochefordiere A, Clough K, Fourquet A, Magdelenat H. Phytoestrogens after breast cancer. Endocr Relat Cancer 2001; 8: $129-34$

127 Jordan $V C, O^{\prime}$ Malley $B W$. Selective estrogen-receptor modulators and antihormonal resistance in breast cancer. J Clin Oncol 2007; 25: $5815-24$

128 Jordan VC. Antiestrogens and selective estrogen receptor modulators as multifunctional medicines. 2. Clinical considerations and new agents. J Med Chem 2003; 46: 1081 - 111

129 Jordan VC. Antiestrogens and selective estrogen receptor modulators as multifunctional medicines. 1. Receptor interactions. J Med Chem 2003; 46: $883-908$

130 Khan N, Afaq F, Mukhtar H. Cancer chemoprevention through dietary antioxidants: progress and promise. Antioxid Redox Signal 2008; 10 : $475-510$

131 Whitsett T, Carpenter M, Lamartiniere CA. Resveratrol, but not EGCG, in the diet suppresses DMBA-induced mammary cancer in rats. J Carcinogen 2006; 5: 15 